\title{
Protective gloves use and work habits of non-professionals handling agricultural pesticides - a survey
}

\author{
Jarmila Hojerová, Martina Beránková, \\ Zuzana Peráčková (neé Klimová), Simona Birbičová \\ Institute of Biotechnology and Food Science, Faculty of Chemical and Food Technology, \\ Slovak University of Technology, Radlinského 9, 81237 Bratislava, Slovak Republic \\ jarmila.hojerova@stuba.sk
}

\begin{abstract}
As many chemicals, also agricultural pesticides (APs) can be hazardous if not used safely. Under typical working conditions, the majority of exposure to the APs is through the hand-skin. Wearing appropriate gloves should be a standard practice when handling the APs. Unlike professionals, amateurs applying the APs in their gardens or vineyards are not trained for the workplace hygiene. In this survey conducted in the spring 2015 across the Slovak Republic, practices regarding the use of protective gloves were obtained. 520 copies of the "paper-and-pencil" questionnaire were distributed to amateur users and specialized stores selling the APs (return rate of $59 \%$ ). A set of ten questions a "closed-ended" or "multiple-choice" type was offered. $75 \%$ of respondents wear gloves when handling the APs. Regrettably, among users wearing gloves, $58 \%$ use the same disposable gloves repeatedly, $67 \%$ wear the reusable gloves from last season, and $53 \%$ do not wash outside of the reusable gloves with detergent before removing them. $30 \%$ of glove users wear all available gloves including absolutely inappropriate materials like fabric and leather, $28 \%$ do not recognize the glove material which they use, $20 \%$ use disposable Latex and $3 \%$ Vinyl and Polyethylene gloves. Only $19 \%$ of glove users wear a material that is generally considered a good choice for handling the APs (7 \% Neoprene \& Latex, $5 \%$ Neoprene, $5 \%$ Nitrile, and $2 \%$ Butyl rubber). The survey showed the need for better education about adequate protective gloves not only for amateur users but also for retailers selling the APs and protective equipment.
\end{abstract}

Keywords: agricultural pesticide, amateur user, skin exposure, protective gloves, survey

\section{Introduction}

The term "agricultural pesticides" (APs) covers a wide-ranging group of "plant protection products" - the most important forms of pesticides. The APs are used in the agricultural sector and home gardens to protect plants from pests and diseases or to control unwanted weeds (EC, 2015). A commercial formulation of an AP is composed of at least one active ingredient or also of other components, such as a synergist and adjuvant. Before an active ingredient can be used within a commercial agricultural pesticide product in the European Union, it must be approved by the European Commission (EC, 2009, 2015).

Many pesticide formulations are on the market today. In general, they are classified and named according to the type of pest they control (e.g. fungicides, insecticides, molluscicides, nematicides, acaricides). They can also be grouped based on the chemical structure of the active ingredient (e.g. organophosphates, carbamates, pyrethroids), the mode of action on target pest (e.g. acetyl cholinesterase inhibitors, calcium channels inhibitors), or risks to the environment and non-target organisms (EC, 2009; WHO, 2010).

\section{Routes of exposure to the APs}

Since the APs are designed to be toxic to specific living organisms, it is likely that some may have levels of human toxicity also. They may enter the human body either indirectly through the oral uptake (as residues in agricultural products and drinking water) or directly through the respiratory tract and through the contact with the skin and mucosal membranes (like eyes). While systemic toxicity of the APs resulting from ingestion and inhalation is relatively well studied, insufficient attention is still given to the dermal exposure.

In fact, it has been shown by a number of studies that, under typical operating conditions in the agricultural sector, most of these exposures occur via the dermal route. Essentially, each formulation of the APs applied as a spray may cause a dermal exposure. But skin contamination may also occur due to a splash, spill or drift when handling an AP and contact with residue on application equipment, protective clothing or treated surfaces. When handling concentrated APs, hazard from skin absorption increases (Aprea et al., 2004; Lebailly et al., 2009; OECD, 2011; Fabian et al., 2012; MacFarlane et al., 2013; Fabian and Binder, 2015; Mieldazys et al., 2015). 


\section{People whose skin can be exposed to the APs}

According to the European Food Safety Authority (EFSA, 2014) in terms of risk of dermal exposure to the APs, there are four groups of persons: operators, workers, bystanders and residents.

1. Operators are persons who are involved in activities relating to the handling pesticide. Such activities include mixing/loading the product into the application machinery, applying the product, and emptying/ cleaning/repairing the machinery/containers after use, all of which can potentially expose the skin of the operator to pesticide (EFSA, 2014). Around $97 \%$ of the total exposure of the body during application of liquid sprays occurs through contact with the skin (Machera, 2014; Fishel, 2015). Evidently, operators should be considered the group that will be at the greatest exposure due to the nature of following activities related to the use of the APs. Operators may be either professional users (such as farmers or contract users engaged in commercial crop production) or amateur users (such as home gardeners) (EFSA, 2014).

Some commercial formulations may be used by both the professionals and the amateurs whereas other formulations of the same pesticide may only be used by a certified, licensed pest control operator. If pesticide package is marked "for use by pest control operators," an amateur user should not use such formulations (EPA, 2013).

2. Workers are persons who, as part of their employment, enter an area that has been treated previously with pesticides or who handle a crop that has been treated with a pesticide.

3. Bystanders are persons who could be located within or directly adjacent to the area where pesticide application or treatment is in the process or has recently been completed; whose presence is quite incidental and unrelated to work involving pesticides, but whose position might lead them to be exposed during a short period of time (acute exposure); and who take no action to avoid or control exposure.

4. Residents are persons who live, work or attend school or any other institution adjacent to the area that is or has been treated with a pesticide; whose presence is quite incidental and unrelated to work involving pesticides but whose position might lead them to be exposed; who take no action to avoid or control exposure; and who might be in the location for up to 24 hours per day (EFSA, 2014).

\section{Health effects of dermal exposure to the APs}

Repeated and long-term dermal effects of hazardous xenobiotics such as the APs, can lead to the denaturation of skin proteins, disorganization of the lipid layers of lamellae, reduction of the intercellular cohesion between skin cells or removal of natural moisturizing factor. As a result of damage, there is a dry and itchy skin with susceptibility to various diseases, or completely damaged skin barrier, which is unable to fulfil its defensive function (Atrux-Tallau et al., 2010; Ngo et al., 2010; Klimová et al., 2012; Collota et al., 2013).

Many APs can penetrate the skin and be absorbed into the skin. After they enter the vascular system (lymphatic and/or blood vessels), they can produce systemic effects, and are capable of causing disease elsewhere in the body (Ngo et al., 2010). The ability to be absorbed vary according to physical and chemical properties of the individual pesticide, dose/time of exposure, anatomical site of the body, skin condition, temperature and humidity of outdoors, presence of other material on the skin, and many other factors (Hojerová et al., 2015). In general, the APs of liquid and emulsifiable formulations are absorbed more readily than those formulated as powders, dusts or granules (Mieldazys et al., 2015). Epidemiological studies have suggested the role of some APs in agriculture-related activities in the occurrence of neurodegenerative disorders like Parkinson's disease (Tanner et al., 2011; Pezzoli and Cereda, 2013; Brouwer et al., 2015; Furlong et al., 2015) and Alzheimer's disease (Hayden et al., 2009), endocrine-disrupting effects (Cocco, 2002; Weiss, 2011), some cancers (Alavanja et al., 2004; Purdue et al., 2007; Collota et al., 2013; Sugeng et al., 2013), etc.

\section{Body surface exposed to the APs}

The amount of the AP deposited on the operator's skin depends on the type of application equipment used. Hand spraying with wide-area spray nozzles is associated with greater operator's exposure than narrowly focused spray nozzles (Baldi et al., 2006; Lebailly et al., 2009; MacFarlane et al., 2013). Due to differences in individual work habits, the distribution of the APs on different parts of the operator's body is also subject to variation. Several studies on the body surface exposure of agricultural operators show that the hands and forearms are the most contaminated parts of the body during preparation and application of pesticides (Lebailly et al., 2009; MacFarlane et al., 2013). When handling the spray-able APs, an exposure of the hands has been shown to account for between 47 and $97 \%$ of the total body (Rawson et al., 2005; Machera et al., 2009). However, the forearms, chest, thighs, and back may also be subject to significant contamination (MacFarlane et al., 2013).

\section{Personal protective equipment to reduce the risk of dermal exposure to the APs}

Since good workplace hygiene may not eliminate all possible exposures, attention should be placed on reducing the probability of direct skin contact through the use of personal protective equipment (PPE). An 
essential method for minimising the hand-skin exposure is the use of appropriate protective gloves.

\section{Types of protective gloves}

There is a variety of gloves for different types of workplace risks, but none of them can protect against all risks. According to intended use, there are medical gloves for health professionals, household cleaning gloves, food service gloves, garden gloves, gloves for working with chemicals and liquids, as well as various gloves for special purposes. Standards, references, and manufacturers use other criteria to classify gloves, such as material, thickness, texture and structure, weight, chemical content, heat and cold protection, mechanical protection, water and chemical protection (Bane, 2015; Fishel, 2015).

With an exception of a few pesticides with "no hazard classification for the operator" (Machera, 2014), the packaging of other APs must include the warning that the suitable protective gloves are required (EC, 2009, 2015; EPA, 2013). Since there is no uniform method for assessing glove resistance to pesticides, the resistance to chemicals is applied. In globally accepted standard ISO 6529: 2013, the material resistance against 13 standard liquid chemicals is assessed by three main indicators: breakthrough time of glove (BTG), permeation rate and cumulative permeation. Long BTG, low permeation rates and low cumulative permeation mass are characteristic for high level barrier materials of gloves against chemical tested (ISO, 2013). The value of BTG generally increases with the thickness of a material.

There are given recommendations on the appropriate type(s) of gloves on the label of the APs product for professional use like "wear chemical-resistant gloves". Specific type of chemically resistant materials or necessary degree of chemical resistance is usually also stated (EPA, 2013; Shaw and Harned, 2013; Black et al., 2014).

However, many packages of home-garden APs contain only general phrase "wear protective gloves", sometimes "wear rubber gloves", and rarely "wear chemical-resistant gloves" or "waterproof gloves" without specifying the recommended glove material.

Employees working with pesticides for professional use and licensed users of the APs shall have received special training in occupational safety. They must be fitted with adequate PPE, including gloves recommended on the product label (EC, 2009, 2015, EPA, 2013). Even though the APs used in home gardens are less hazardous than those which are usually used by professional operators, it should be emphasized that the amateur users are not trained for work with pesticides. So they are left to themselves to manage their workplace hygiene.
Based on this, we have conducted a survey to obtain information on amateur users' working practices related to protective gloves when applied the APs in typical home-garden situations.

\section{Materials and Methods}

The survey was carried out between March and May 2015 in various regions in the Slovak Republic. 520 copies of the "paper-and-pencil" questionnaire were distributed in two ways. First one went through personal contact with amateur individuals who used the APs in their home garden, vineyard and greenhouse (70 copies). Second one went through personal distribution to garden centres and specialized stores selling the APs for amateur use (450 copies). Here shop assistants were asked to offer the questionnaire to their customers who use the APs; these questionnaires were filled out directly in the shop. All completed questionnaires were collected at the end of May 2015.

A set of ten questions was designed for easy and quick completion using "closed-ended" type of questions (Q). The questions No. 1-4 and 6-10 were offering answers "Yes" or "No". The question No. 5 was "multiple-choice" type: respondent could mark one from 8 options, and, moreover, he was free to express his own answer.

\section{Results and Discussion}

Of the 520 questionnaires distributed, 305 of completed ones were returned, giving a response rate of $59 \%$. Responses to the survey questions were summarised using percentages.

Q1: Do you wear any protective gloves when handling agricultural pesticides (APS)?

Results: $75 \%$ of the 305 amateur users surveyed (i.e. 229) answered "Yes", 25 \% "No" or rarely.

Discussion: Due to the fact that amateur users need not be informed about the risks of exposure to pesticides on human health and the opportunities for adequate protection, the recommendations on the label of the APs for home garden use should be sufficiently informative (HSE, 2014). However, $25 \%$ of users do not wear gloves when handling the APs. So either the information on the pesticide label is insufficient or users have little interest in reading and interpreting the label statements.

Q2: Do you wear the same disposable gloves for handling the APs more than one-times?

Results: 58 \% of 229 respondents, who reported use of protective gloves, answered "Yes", 42 \% "No". 
Discussion: Disposable gloves (for single use) are usually made of light-weight plastic material. Those are gloves made of polyvinyl chloride (PVC, vinyl) and polyethylene (PE) for the food service, cleaning, hair colouring, as well as natural rubber (Latex) gloves for medical use or Nitrile gloves for various purposes. They are typically thinner $(0.06-0.2 \mathrm{~mm})$ than the reusable ones $(0.4-0.8 \mathrm{~mm})$ (Fishel, 2015), so that the handling of the product is often more comfortable. Disposable gloves should be appropriate to protect hand-skin during a short-term application of mild skin irritants like the slightly toxic APs. They are low cost, thus can be discarded after a single use and demand no maintenance. However, most of disposable gloves have poor mechanical and chemical resistance. Although traditionally less elastic than Latex gloves, disposable Nitrile (acrylonitrile butadiene) rubber gloves are more puncture-resistant and chemical-resistant, so may be appropriate for single use when handling the home garden APs. But in our survey most users indicated that they wear the same disposable gloves repeatedly what is definitely incorrect.

Q3: Do you wear the reusable gloves used last season to handle the APs?

Results: 67 \% of 229 glove users answered "Yes", 33 \% "No".

Discussion: The reusable protective gloves made of chemical-resistant material are generally suitable for handling APs. But contaminated glove material can be degraded during long-term storage. Moreover, because most materials are able to absorb some pesticide residues over time, they serve as a reservoir of those pesticides during future use. Therefore, gloves used in the previous season are not safe and should be replaced.

Q4: When buying a protective glove, do you interest yourself in appropriate material for the APs handling?

Results: 63 \% of 229 glove users answered "Yes", 37 \% "No".

Discussion: Each glove material has its own advantages and disadvantages. Choosing gloves depends on the toxicity of pesticide, type and period of application. Gloves made of cotton, leather, canvas, or other absorbent materials are absolutely inappropriate, because they increase chance of pesticide exposure. The waterproof gloves do not provide adequate protection from all pesticides. For more than slightly toxic APs (see discussion on $Q$ No. 2), chemical-resistant gloves are necessary. The unlined gloves made of Nitrile rubber (disposable and reusable) and reusable Neoprene ${ }^{\circledR}$ \& Latex are a good choice when considering reasonable price and chemical resistance.
In general, unlined, reusable liquid-proof polychloroprene/Neoprene ${ }^{\circledR}$ rubber, Butyl rubber, and Barrier laminate gloves with tops that extend well up on the forearm are the best for handling hazardous and dangerous APs. These synthetic materials provide good protection under most conditions; they are durable, and reasonably priced. The Barrier laminate glove offers the most protection against the APs. It consists of two or more different materials that are laminated or blended together (Bauer et al., 2009; EPA, 2013). Fluorocarbon/Viton ${ }^{\circledR}$ is another good choice, but is more expensive than most other chemicalresistant gloves (Bauer et al., 2009). The thickness of chemical-resistant glove for the APs should be at least $0.35 \mathrm{~mm}$ (Fishel, 2015). Finally, it is noteworthy that along with their protective parameters, gloves should have adequate ergonomic properties, suitable for a particular application (Irzmanska and Stefko, 2015). Several respondents stated that they do not feel comfortable at work, when they are wearing gloves.

Q5: If you wear gloves when handling the APs, which material do use most often?

Results: 229 of glove users indicated material of the gloves as it is shown in Figure 1.

Discussion: Even up to $30 \%$ glove users indicated that they wear any available gloves: regardless of whether they are made of synthetic material, rubber, leather, cotton or canvas. It should be emphasized that gloves made of leather and fabric absorb pesticides, so they increase the risk of dermal exposure to pesticides.

Only $42 \%$ of glove users indicated that they are able to identify glove material that they use when handling the APs (Fig. 1). Thin Latex gloves have been indicated as the most common type (20\%). This material has good flexibility and is comfortable to wear, which makes it popular generalpurpose gloves. However, along with Vinyl and PE gloves (3\%), the Latex gloves do not provide adequate skin protection and are disintegrated rapidly (EPA, 2013). Moreover, proteins in natural latex may cause skin allergic reactions in some individuals. Few of the glove users identified as the most frequent material used by them Neoprene ${ }^{\circledR}$ \& Latex (7 \%), Neoprene ${ }^{\circledR}(5 \%)$, Nitrile (5\%), and Butyl rubber (2\%). Illustration of the glove materials used by some respondents of the survey is shown in Fig. 2. Viton ${ }^{\circledR}$ and Barrier laminate gloves, which are recommended for the application of dangerous pesticides by professional operators (Fishel, 2015), were not included as options in our survey for amateur users due to their high price. 


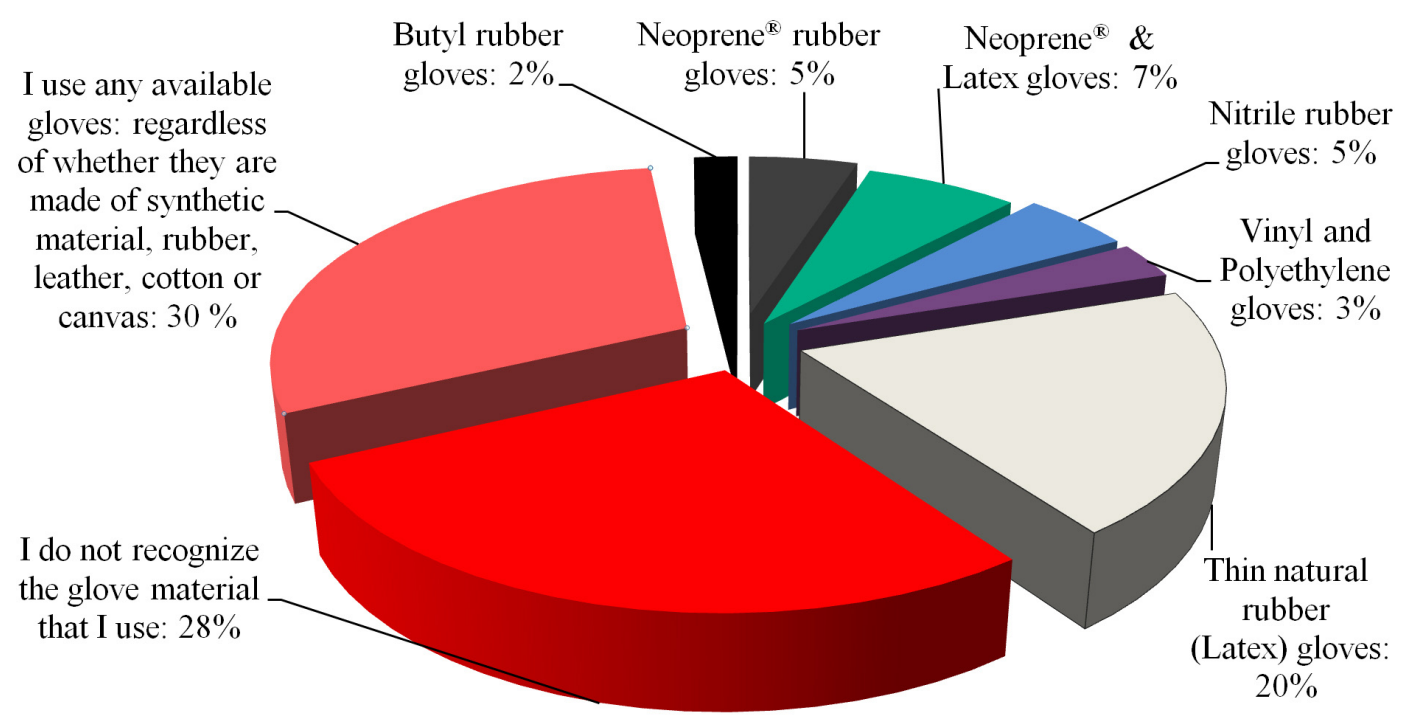

Fig. 1. Glove materials most often worn by 227 amateur users according to the survey.

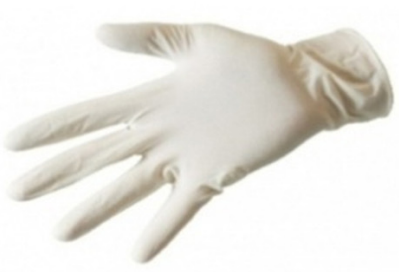

Thin Latex glove

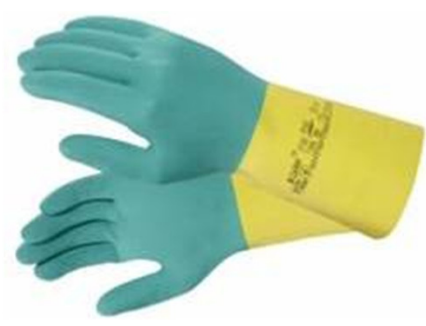

Neoprene \& Latex gloves

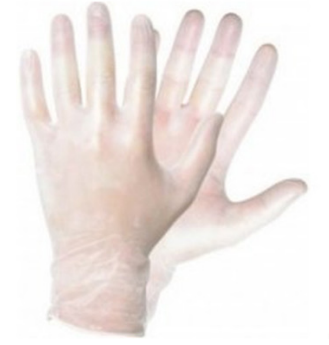

Thin Vinyl gloves

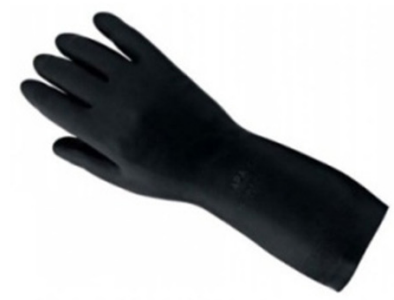

Neoprene glove

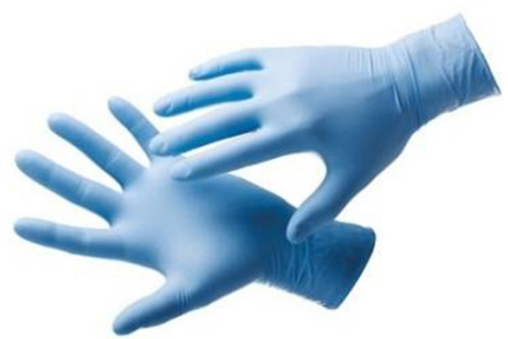

Nitrile rubber gloves

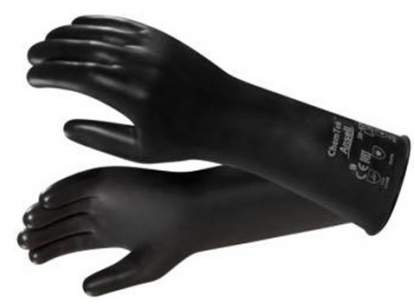

Butyl rubber gloves

Fig. 2. Illustration of glove materials used by some amateur users of the survey.

Q6: After handling the APs, do you wash outside of gloves with detergent before removing them?

Results: $47 \%$ (142) of 229 glove users answered "Yes", 53 \% "No".

Discussion: Users should wash reusable gloves with soap and warm water while still wearing them, and only then remove them to avoid accidental skin contamination when used next time (Bauer et al., 2009, EPA, 2013). According to our survey, only $27 \%$ of the amateur users adhere to such hygiene practices.

Q7: Did you ever consult the need to use protective gloves for handling the APs with the shop assistant?

Results: $44 \%$ (101) of 229 glove users answered "Yes, 56 \% "No".
Discussion: It is striking that only a minor of surveyed users have done consultations with shop assistants.

Q8: If you requested the shop assistant for help when choosing gloves for handling the AP, was he competent enough? Results: $35 \%$ of 101 glove users, who responded positively to the question No. 7, answered "Yes", 65 \% "No".

Discussion: This result is not a good sign for professionalism of retailers supplying the APs for home garden use as well as the protective gloves. It is evident that also in this field is the need to increase knowledge probably through appropriate training (Yang et al., 2014). 
Q9: Did you have an allergic reaction or other forms of rash on your skin which can be linked to the application of the APs?

Results: 27 \% of 305 amateur users answered "Yes", 73 \% "No".

Discussion: Three major types of the APs-skin interactions may occur from the aspect of health risks: (i) local traumas: ranging from skin irritation through skin rashes and burns to permanent degradation of the skin barrier (skin corrosion); (ii) local/systemic traumas: ranging from skin sensitization through complex immune system (allergic contact dermatitis, mainly eczema) responses to skin cancer; (iii) systemic traumas (Atrux-Tallau et al., 2010; Ngo et al., 2010). Due to insufficient use of appropriate gloves we were not surprised that up to $27 \%$ respondents mentioned skin damage in connection with the application of the APs.

Q10: Do you use a respirator or protective drapes when spraying agricultural pesticides?

Results: $33 \%$ of 305 amateur users surveyed answered "Yes", 67 \% "No".

Discussion: Certain pesticides may be inhaled in sufficient amounts to cause serious damage to nose, throat, lung tissues or to be absorbed through the lungs to the bloodstream. The hazard of poisoning by inhalation is high because of rapid and complete absorption of pesticides through the mucosa. It is required to wear an appropriate and properly fitting respirator.

\section{Conclusion}

In the first part of this paper, risks from dermal exposure, in particular the hand-skin exposure, to agricultural pesticides (APs) are discussed. Chemical-resistant synthetic rubber gloves are an important equipment to keep pesticides away from the hand skin of user. Garden gloves, medical gloves, household cleaning gloves, food service gloves, and gloves made of fabric or leather are inadequate for handling the APs.

In the second part of this paper, the results of the questionnaire survey that was focused on the use of work gloves and on other behaviour of non-professional users of these chemicals are given. Three major findings can be drawn from this survey.

Firstly, it is encouraging that majority (75\%) of surveyed amateur users already wear protective gloves when handling the APs in their home gardens, small vineyards and greenhouses.

Secondly, it is worrying that the choice of glove material by them is usually inappropriate. Only $19 \%$ of respondents, who wear gloves, use a type of material that is generally recognized as appropriate (i.e. some type of chemical resistant gloves). $30 \%$ of respondents use any available gloves regardless of whether they are made and $28 \%$ of respondents do not recognize the glove material that they use. We consider that the reason may revolve around (i) the insufficient information on the packaging of many APs in terms of appropriate protective gloves and (ii) little interest in some amateur users to read and interpret a statement on the product label before they buy or use it.

Thirdly, the efforts should be made to increase the educational level on adequate protective glove use and hygiene habits not only in amateur users, but also in retailers who sell the APs and protective gloves to these users.

\section{Acknowledgement}

This study was supported by grant of the Ministry of Education, Science, Research and Sport of the Slovak Republic VEGA number 1/0593/14: "Implementation of the OECD in vitro method for the dermal absorption assessment of pesticides and its modification for the evaluation of working gloves resistance against pesticide".

\section{Abbreviations}

APs, Agricultural pesticides; BTG, breakthrough time of glove; EC, European Commission; EFSA, European Food and Safety Authority; EPA, United States Environmental Protection Agency; EUOSHA, European Agency for Safety and Health at Work; HSE, United Kingdom Health and Safety Executive; ISO, International Organization for Standardization; OECD, Organisation for Economic Co-operation and Development; PPE, Personal protective equipment; WHO, World Health Organization.

\section{References}

Alavanja MC, Hoppin JA, Kamel F (2004) Ann. Rev. Public Health, 25: 155-197.

Aprea C, Terenzoni B, De Angelis V, Sciarra G, Lunghini L, Borzacchi G, Vasconi D, Fani D, Quercia A, Salvan A, Settimi L (2004) Arch. Environ. Contam. Toxicol., 48: $127-134$.

Atrux-Tallau N, Romagny C, Padios K, Denis A, Haftek M, Falson F, Pirot F, Maibach HI (2010) Arch. Dermatol. Res., 302: 435-441.

Baldi I, Lebailly P, Jean S, Rougetet L, Dulaurent S, Marquet P (2006) J. Expo. Sci. Environ. Epidemiol., 16: $115-124$.

Bauer EC, Ogg CL, Sandall LL (2009) Pesticide Safety: Choosing the right gloves. Available in September 2015 at: http://www.ianrpubs.unl.edu/pages/ publicationD.jsp?publicationId=1209.

Black C, Shaw A, Harned C, Coffman ChW (2014) J. Pesticide Safety Educ., 18: 17-26. 
Brouwer M, Koeman T, van den Brandt PA, Kromhout H, Schouten LJ, Peters S, Huss A, Vermeulen R (2015) Occup. Environ. Med., 72: 448-455.

Cocco P (2002) Cad. Saude Publica, 18: 379-402.

EC (2009) Regulation (EC) No. 1107/2009 of 21 October 2009 concerning the placing of plant protection products on the market. Off. J. L 309: 50 pp.

EC (2011) Regulation (EC) No. 547/2011 regards labelling requirements for plant protection products. Off. J. I 155: 205 pp.

EC (2015) Plant Protection Product. Available in September 2015 at: http://ec.europa.eu/food/plant/ pesticides/index_en.htm.

EFSA (2014) EFSA Journal, 12: 3874/1-55.

EPA (2013) Label Review Manual, Chapter 10: Worker protection labeling. Available in September 2015 at: http://www2.epa.gov/pesticide-registration/labelreview-manual.

Fabian CL, Santos GG, Leuenberger F, Nuyttens D, Binder CR (2012) Sci. Total Environ., 430: 202-208.

Fabian CL, Binder CR (2015) Int. J. Environ. Research Public Health, 12: 4670-4696.

Fishel FM (2015) Glove Selection for Working with Pesticides. UF/IFAS Extension. PI-120. Available in September 2015 at: http://edis.ifas.ufl.edu/.

Furlong M, Tanner CM, Goldman SM, Bhudhikanok GS, Blair A, Chade A, Comyns K, Hoppin JA, Kasten M, Korell M, Langston JW, Marras C, Meng Ch, Richards M, Ross GW, Umbach DM, Sandler DP, Kamel F (2015) Environ. Int., 75: 144-150.

Hayden KM, Norton MC, Darcy D, Ostbye T, Breitner JC, Welsh-Bohmer KA (2009) Alzheimer's \& Dementia, 5: 128-129.

Hojerová J, Peráčková Z, Beránková M (2015). Proceedings of the International Conference of Cosmetology. Ed. Czech Society of Cosmetology, Frymburk: 4-8.

HSE (2014) Labelling Handbook. Volume 3: Requirements for Amateur Product Labels, Health and Safety Executive, London, 111-134.

Irzmanska E, Stefko A (2015) Int. J. Ind. Ergon., 47: $61-71$.

ISO (2013) ISO 6529:2013(E). Determination of resistance of protective clothing materials to permeation by liquids and gases. Third edition. Technical Committee ISO/TC 94, Geneva.
Klimová Z, Hojerová J, Lucová M, Pažoureková S (2012) Acta Chim. Slovaca, 5: 70-74.

Lebailly P, Bouchart V, Baldi I, Lecluse Y, Heutte N, Gislard A, Malas JP (2009) Ann. Occup. Hyg., 53: 69-81.

MacFarlane E, Carey R, Tessa Keegel T, El-Zaemay S, Fritschi L (2013) Safety Health Work, 4: 136-141.

Machera K, Tsakirakis A, Charistou A, Anastasiadou P, Glass CR (2009) Ann. Occup. Hyg., 53: 573-584.

Machera K (2014). PPE Requirements and Pesticides Labelling. Conference on Safe and Sustainable Use of Pesticides, Beograde, 77 pp.

Mieldazys A, Mieldazys R, Vilkevicius G, Stulginskis A (2015) Agriculture - Use of pesticides/plant protection products. EU-OSHA. Available in September 2015 at: http://oshwiki.eu/wiki/Agriculture_-_Use_of_ pesticides/plant_protection_products

Ngo MA, O’Malleya M, Maibach HI (2010) J. Appl. Toxicol., 30: 91-114.

OECD (2011) Guidance Notes on Dermal Absorption. Test No. 156. Organisation for Economic Co-operation and Development iLibrary, Paris, 72 pp.

Pezzoli G, Cereda E (2013) Neurology, 41: 2035-2042.

Purdue MP, Hoppin JA, Blair A (2007) Int. J. Cancer, 120: 642-649.

Shaw A, Harned C (2013) J. Pesticide Safety Educ., 15: $17-29$.

Sugeng AJ, Beamer PI, Lutz EA, Rosales CB (2013) Sci. Total Environ., 0: 35-41.

Tanner CM, Kamel F, Ross GW, Hoppin JA, Goldman SM, Korell M, Marras C, Bhudhikanok GS, Kasten M, Chade AR (2011) Environ. Health Perspect., 119: $866-872$.

Weiss B (2011) J. Neurol. Sci., 305: 11-21.

WHO (2010) The WHO recommended classification of pesticides by hazard and guidelines to classification 2009, Geneva: 78 pp.

Yang X, Wang F, Meng L, Zhang W, Fan L, Geissen V, Ritsema CJ (2014) Sci. Total Environ., 497/498: 172-179. 